SHORT REPORT

\title{
Peroperative frozen section analysis of TTF-1 antigen expression
}

\author{
S Camilleri-Broet, M Alifano, M Morcos, E Comperat, P Magdeleinat, B Marmey, T J Molina, \\ J-F Régnard, J Audouin
}

J Clin Pathol 2004:57:98-100

Background: The assessment of thyroid transcription factor 1 (TTF-1) expression is a useful way to investigate the origin of lung adenocarcinomas or large cell carcinomas when dealing with a solitary lung nodule in a patient with a history of extrathoracic cancer. However, if immunohistological analysis has not been performed before surgery, a peroperative frozen section may be insufficient to distinguish between a primary pulmonary tumour and a metastatic tumour.

Aims: To develop a technique for the rapid assessment of TTF-1 expression that could improve the ability of frozen section peroperative histological diagnosis to answer such questions.

Methods: A rapid immunohistochemical technique (lasting 30 minutes) to assess the expression of TTF-1 was developed and tested.

Results: Among the 45 interpretable cases, results of frozen section immunohistochemistry were similar to those found by the standard immunohistochemical technique for the expression of TTF-1.

Conclusions: This technique enables TF-1 to be analysed peroperatively, but further prospective studies are needed to assess its usefulness in routine practice.

$\mathrm{T}$ he lung is one of the most frequent sites of metastasis for extrathoracic tumours. Among tumours that can metastasise to the lung, some adenocarcinomas (such as colon and renal cell tumours) are of special interest because of the potential benefit of surgery in terms of a cure. ${ }^{1-3}$ Although the most common presentation is multiple nodules, solitary metastasis does occur. In this case, the distinction between solitary metastasis and primary lung cancer remains the major task, because it carries different therapeutic options (lobectomy for primary lung cancer, wedge resection for metastatic lesions). The differential diagnosis is based on clinical (smoking habit, stage, and clinical history of the previous tumour), radiographic, and histological features. In the case of adenocarcinomas or large cell carcinomas, the distinction can be difficult, even at classic histological examination. In such cases, positivity for thyroid transcription factor l (TTFl; a protein normally expressed in thyroid and lung parenchyma) is thought to indicate the primary lung origin of the tumour. ${ }^{4-6}$ Our report deals with the technical feasibility and preliminary results of assessment of TTF-1 on peroperative frozen sections.

"In the case of adenocarcinomas or large cell carcinomas, the distinction can be difficult, even at classic histological examination"

\section{MATERIAL AND METHODS \\ Material}

Fifty consecutive cases received in the laboratory for peroperative frozen section examination were analysed (table 1). Fresh tissue was slow frozen, cut into $4 \mu \mathrm{m}$ thick sections in a cryostat, and routinely stained with May Grünwald Giemsa

\section{Peroperative frozen section TTF-1 expression assessment}

An adjacent section to the routine one was used for the peroperative frozen immunohistochemical technique. After drying (under a hand dryer), slides were briefly rehydrated and incubated with the primary antibody raised against the TTF-1 protein (TEBU; Novocastra, Newcastle upon Tyne, UK) at the usual dilution (1/100) for five minutes. A standard streptavidin-biotin-peroxidase complex (SABC) method was applied using a commercially available kit (ABCYS GMR4-61; Biospa, Milano, Italy), with a five minute incubation for both steps (second antibody and SABC). The staining was visualised using diaminobenzidine, and the slides were counterstained with Mayer's haematoxylin. Stained nuclei of normal lung tissue were used as internal positive controls. The technique took less than 30 minutes to perform.

\section{Classic TTF- 1 immunohistochemistry assessment}

In all cases, TTF-1 expression was also assessed on $4 \mu \mathrm{m}$ thick sections from formalin fixed and paraffin wax embedded material. The sections were pretreated in a microwave, incubated for two hours with the anti-TTF-1 antibody, and staining was visualised by the standard SABC method. Classic immunohistochemistry was interpreted without knowledge of the peroperative frozen section TTF-1 results.

\section{RESULTS (TABLE 1)}

The final pathological diagnoses were: primary lung carcinoma, 34 cases; lung metastasis, 11 cases; malignant mesothelioma, two cases; and non-neoplastic lesion, three cases. Five cases could not be interpreted because of either the absence of neoplastic cell proliferation (three) or nonvalid negativity of the tumour cells in the absence of an internal positive control (two). One of this last group was a TTF- 1 expressing lung adenocarcinoma. The second was a TTF-1 negative renal clear cell carcinoma metastasis.

Figures 1 and 2 show typical staining patterns for negative and positive specimens, respectively, stained using the preoperative frozen section method.

Among the remaining 45 cases, 23 were positive for TTF-1 on both techniques (peroperative frozen and classic paraffin

Abbreviations: SABC, streptavidin-biotin-peroxidase; TTF-1, thyroid transcription factor 1 


\begin{tabular}{|c|c|c|c|}
\hline & Number & $\begin{array}{l}\text { Peroperative } \\
\text { TF-1 positive }\end{array}$ & $\begin{array}{l}\text { Paraffin wax } \\
\text { embedded } \\
\text { tissue TTF-1 } \\
\text { positive }\end{array}$ \\
\hline Primary lung cancer & 34 & & \\
\hline Adenocarcinoma & 18 & $17^{*}$ & 18 \\
\hline Large cell carcinoma & 4 & 2 & 2 \\
\hline $\begin{array}{l}\text { Squamous cell } \\
\text { carcinoma }\end{array}$ & 8 & 0 & 0 \\
\hline $\begin{array}{l}\text { Neuroendocrine } \\
\text { tumour }\end{array}$ & 4 & 3 & 3 \\
\hline Metastases & 11 & & \\
\hline Colonic & 8 & 1 & 1 \\
\hline Kidney & 2 & $0^{*}$ & 0 \\
\hline Breast & 1 & 0 & 0 \\
\hline Malignant mesothelioma & 2 & 0 & 0 \\
\hline No tumour & 3 & ND & ND \\
\hline Total & 50 & 23 & 24 \\
\hline
\end{tabular}

ND, not done, TTF-1, thyroid transcription factor 1 .

*Two case were not interpreted using the peroperative technique because of the absence of an internal positive control.

wax embedded tissue). All of the positive cases except for one were primary lung carcinomas, namely: 17 of 17 adenocarcinomas, two of four large cell carcinomas, three of four neuroendocrine tumours (two large cell neuroendocrine carcinomas and one typical carcinoid tumour). In contrast, there was no expression of TTF-1 in the eight squamous cell carcinomas.

One metastastic colonic carcinoma was positive for TTF-1 on both the peroperative frozen and classic paraffin wax embedded slides. The diagnoses of pulmonary metastatic lesions were established on history and histological features of well differentiated gland forming adenocarcinoma with characteristic colonic crypts and a CK7-/CK20+ profile.

The intensity of staining for TTF-1 was similar in peroperative frozen and classic paraffin wax embedded tissues. In some cases, wide areas of necrosis were the cause of non-specific staining.

\section{DISCUSSION}

Our method of assessment of TTF-1 expression on peroperative frozen sections is rapid and sensitive. We found that this

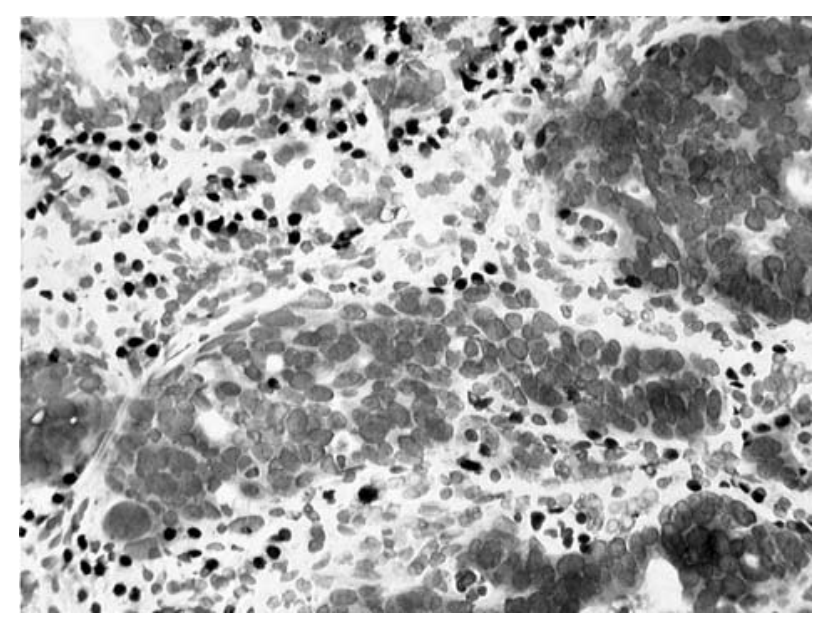

Figure 1 Peroperative assessment of thyroid transcription factor 1 expression on frozen tissue. Metastatic colonic adenocarcinoma showing negative fumour cells with internal positive controls.

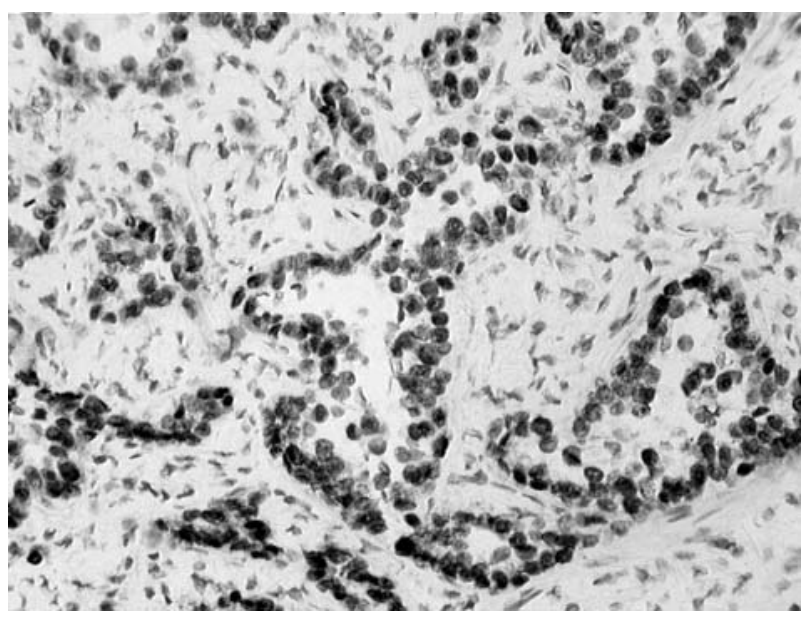

Figure 2 Peroperative assessment of thyroid transcription factor 1 (TTF-1) expression on frozen tissue. Primitive lung adenocarcinoma showing high expression of TTF-1.

\section{Take home messages}

- The results of immunohistochemistry for thyroid transcription factor 1 (TTF-1) expression were similar for peroperative frozen sections and standard paraffin wax embedded material

- This technique enables TTF-1 to be analysed, but further prospective studies are needed to assess its usefulness in routine practice

technique was more reliable on peroperative frozen sections than on previously frozen material (data not shown), because of better sensitivity and preservation of cell morphology. The reliability of the method was assessed by internal positive controls and comparison with the adjacent classically stained slide.

"Our method of assessment of thyroid transcription factor 1 expression on peroperative frozen sections is rapid and sensitive ${ }^{\prime \prime}$

Peroperative TTF-1 staining must be interpreted taking into account other diagnostic elements (history, radiological aspect) and the histological subtype. TTF-1 is negative in most squamous cell carcinomas, but it is well known that the absence of TTF-1 expression does not exclude a primary lung origin of an adenocarcinoma or a large cell carcinoma. With respect to specificity, our data confirm the good (but not perfect) performance of TTF-1 expression, in agreement with other studies dealing with the classic method of detection. ${ }^{78}$ However, further studies need to be performed to answer the question of the usefulness of this technique in the frozen section diagnosis process, and whether such a technique would have an influence on the attitude of the surgeon intraoperatively, when dealing with the differential diagnosis between primary lung or metastatic tumours.

\section{ACKNOWLEDGEMENTS}

Many thanks to Dr MC Charpentier for her involvement in the lung pathology and Dr JF Emile for anti-CK7 CK20 immunohistochemistry. The authors also wish to thank $\mathrm{P}$ Bonjour for her expert technical help. 


\section{Authors' affiliations}

S P Camilleri-Broet, M Alifano, M Morcos, E Comperat, P Magdeleinat, B Marmey, T J Molina, J-F Régnard, A Josée, Service d'Anatomie Pathologique et Unité de Chirurgie Thoracique, Hotel-Dieu, 1, Place Du Parvis Notre Dame, Cedex 75181, Paris, France

Correspondence to: Dr S P Camilleri-Broet, Service d'Anatomie Pathologique, Hotel-Dieu, 1 , Place Du Parvis Notre Dame, Cedex 75181, Paris, France; sophie.camilleri-broet@htd.ap-hop-paris.fr

Accepted for publication 2 June 2003

\section{REFERENCES}

1 Robinson BJ, Rice TW, Strong SA, et al. Is resection of pulmonary and hepatic metastases warranted in patients with colorectal cancer? J Thorac Cardiovasc Surg 1999;117:66-75.

2 Pastorino U, Buyse M, Friedel G, et al. Long-term results of lung metastasectomy. Prognostic analyses based on 5206 cases.
The international registry of lung metastases. J Thorac Cardiovasc Surg 1997; 113:37-49.

3 Pfannschmidt J, Hoffmann H, Muley T, et al. Prognostic factors for survival after pulmonary resection of metastatic renal cell carcinoma. Ann Thorac Surg 2002;74:1653-7.

4 Chhieng D, Cangiarella JF, Zakowski MF, et al. Use of thyroid transcription factor $1, P E-10$, and cytokeratins 7 and 20 in discriminating between primary lung carcinomas and metastatic lesions in fine-needle aspiration biopsy specimens. Cancer 2001:93:330-6.

$5 \mathrm{Ng} \mathrm{WK}$, Chow HCY, Ng P. Thyroid transcription factor-1 is highly sensitive and specific in differentiating metastatic pulmonary from extrapulmonary adenocarcinoma in effusion fluid cytology specimens. Cancer 2002:96:43-8.

6 Bohinski RJ, Bejarano PA, Balko G, et al. Determination of lung as the primary site of cerebral metastatic adenocarcinomas using monoclonal antibody to thyroid transcription factor-1. J Neurooncol 1998;40:227-31.

7 Reis-Filho JS, Carrilho C, Valenti C, et al. Is TTF- 1 a good immunohistochemical marker to distinguish primary from metastatic lung adenocarcinomas? Pathol Res Pract 2000;196:835-40

8 Bejarano PA, Baughman RP, Biddinger PW, et al. Surfactant proteins and thyroid transcription factor-1 in pulmonary and breast carcinomas. Mod Pathol 1996:9:445-52. 